Article

\title{
Ensuring the Sustainability of University Learning: Case Study of a Leading Chinese University
}

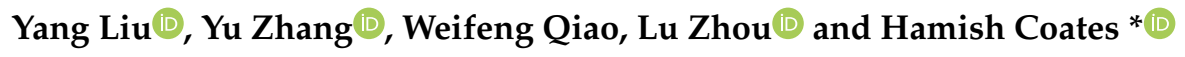 \\ Institute of Education, Tsinghua University, Beijing 100084, China; liuyang2019@tsinghua.edu.cn (Y.L.); \\ zhangyu2011@tsinghua.edu.cn (Y.Z.); qiaoweifeng@tsinghua.edu.cn (W.Q.); \\ zhoul19@mails.tsinghua.edu.cn (L.Z.) \\ * Correspondence: hamishcoates@tsinghua.edu.cn
}

Received: 27 July 2020; Accepted: 21 August 2020; Published: 26 August 2020

\begin{abstract}
The spread of the novel coronavirus at the start of 2020 shocked higher education across China then around the rest of the world. To ensure sustainability of learning, this required an unprecedented shift from campus-based to emergency online education. This created an urgent need to learn more about the quality of online education, the provision of global education, and the transformation potential of universities. This paper analyses these matters, presenting insights from large-scale research conducted on a leading Chinese university, the first ever major research university to make this substantial transition. This research applied a mixed methods design, which combines quantitative and qualitative approaches. The results provide important insight into the nature, quality, and outcomes of online learning in major Asian research universities. They signal critical areas that require reform to ensure the sustainability of future higher education.
\end{abstract}

Keywords: COVID-19; online education; education evaluation; higher education

\section{Introduction}

\subsection{Designing Education Innovation}

The spread of the novel coronavirus at the start of 2020 shocked higher education across the world. To keep people apart and ensure the sustainability of learning, governments implemented social distancing and self-isolation measures, which emptied campuses, causing students and faculty to work from home. This pandemic provoked a rapid shift to emergency forms of online learning among major education systems, institutions, faculty, and students.

This crisis is one of the largest shocks to higher education in living memory. Occurring at the peak of globalization, it may be the largest ever. Even after just a few months, the world's most eminent higher education scholars and leaders recognize that universities are likely to be impacted so dramatically that they will be fundamentally different after the pandemic [1,2]. Every facet of higher education has been touched, from student wellbeing and characteristics, to campuses and global research, to faculty characteristics and work, to university funding and policy. The economic implications will ricochet for years, perhaps even signaling a new era for higher education and the communities that it serves.

Such a shock drives an unprecedented need to investigate the nature of higher education. These developments call for urgent and expansive research. To this end, a comprehensive institution-wide program of higher education policy research was launched in early February 2020 at one of China's leading universities. Broadly, this research sought to unpack what had happened, what was going on, and what lessons could be gleaned to guide post-pandemic innovation. An array of methods was involved, including a census of students and of faculty, analysis of policy documents and practices, 
production of institutional case studies, study of learning analytics and platforms, and interviews with university leaders. This paper reports key results from the student and faculty censuses and leader interviews. It documents one of the largest education transformations to ensure education sustainability at a prestigious global university.

It is important to stress at the outset that this research was about university education and people first and foremost, and only secondly about online technology. This is important because, despite ongoing interest in technology, it is people and institutions that make education successful, not computers. Technology can play an important enabling role, although it is most successful when it is directed by academic leaders rather than by technical or commercial interests $[3,4]$. Indeed, the maturation of EdTech has meant that, particularly in the last five years, technology has started focusing on education rather than the other way around [5]. Rather than focusing on technology, contemporary academic leaders have started leveraging a range of different platforms and education experts to enable students and teachers to engage in more productive forms of higher education.

\subsection{The University Case}

The research focuses on the case of a leading Chinese university. Over the last two decades, this university has grown into one of the world's most prestigious universities [6]. It is gated, highly intensive, residential, and research productive. It is a high-tech university, although hitherto without formal online education.

In late January 2020, it became apparent to the university leaders that a novel coronavirus was likely to impact normal university operations in the coming months. At a university-wide academic leadership meeting, it was decided that the university would become the first of the world's most prestigious universities to evacuate the campus and shift all coursework education online. The intent, broadly, was to implement emergency online learning to ensure safety and progress the upcoming semester as usual. In early February, days after nearly all students and faculty left for the Spring Festival holiday, the academic leaders gave the 'first formal online class' to more than 50,000 students and 10,000 faculty and staff. Faculty, staff and students, many with no formal online education experience, were given two weeks to prepare. In the following months, almost 2700 faculty delivered 4000 online courses to 25,000 students spread across every time zone and continent. It is important to qualify that top-quality online education has matured markedly in recent years, as just noted, and that much of what is referred to in this paper is better referred to as 'emergency online education'.

This university did not spring into formal emergency online education in a vacuum, without resources or without an eye to the future. As a premier technical university, it plays a huge role in creating, designing and distributing education technology. Its global ranking in computer science is among the highest in the world [7]. It is located in the heart of the world's biggest multi-billion-dollar EdTech ecosystem [8].The university is a pioneer in education technology in China, having developed global online and mobile learning platforms with innovative pedagogical and business models. Its engagement in education technology encompasses teaching and learning, basic and applied research, innovation, social service, and entrepreneurial spin-offs. So, while much formal education at the university remained very traditionally campus-based, it was already very technologically infused.

This paper reports on single-institution research, but this research and its contributions are notable for many reasons. Given the timing of the shock and academic calendar, the university appears to have been the first of the world's major research universities with a diversified curriculum to shift into emergency online learning. It is likely the first time that one of the world's most prestigious, gated, and residential universities has shuttered the campus and shifted education entirely online. Beyond a small selection of distance education institutions, China has had few formal policies regarding formal online university education. The highly stratified nature of the Chinese university system means that the university plays an important signaling and service function, both for education experimentation and for propagating education resources. Looking beyond China, this was the first 
time that a major higher education system in Asia embraced emergency online learning as part of formal education provision. Unlike other prestigious universities, particularly in Anglospheric countries, while highly tech-savvy, the faculty and students have little experience of online education. Given the elite STEM-emphasis of the university's programs, placing much emphasis on creative discovery and collaboration, a great deal of education involved informal, individualized, 'high-touch', and global forms of education. Finally, and not least, the university has made several global commitments to sustainability in all its forms, from academic focus and functions, to campus operations, to research and partnerships. This research helped ascertain the viability of transformed operations.

\subsection{Research Perspectives and Questions}

The research commenced with university-wide planning, the formation of leadership and advisory structures, and the specification of detailed administration arrangements. The technical work involved environmental scanning and conceptual design, instrument development and validation, population specification and enumeration, fieldwork and quality monitoring, and analysis and reporting.

The overarching aim of the research was to identify the nature of the education transformation and to identify its implications for the future of high-quality and blended higher education. The specific objectives were to generate advice for university leaders, bridge research into quality assurance and online education, and contribute evidence to assist with post-pandemic policy formation. Three research questions were specified:

(a) What were foundation education experiences, qualities, and achievements?

(b) What are the experiences, qualities, and achievements of emergency online education?

(c) What can be learned about design scenarios for the sustainability of future higher education?

Theory helps make sense of changing phenomena, particularly during crises. As suits much policy and institutional research, an early design decision was made to be theoretically eclectic, pragmatic, and agile. This large study integrates existing research in fields like education evaluation, online learning, education quality, foresight analysis, student experience, learning outcomes, education technology, academic work roles and practices, university leadership, and management information. Cantwell, Coates and King [9] and Hazelkorn, Coates and McCormick [10] present the nature and diversity of the conceptual perspectives engaged.

\section{Methods}

\subsection{Design and Framework}

The methodology was designed to underpin the conceptual design. Broadly, the research took the form of a natural experiment, whereby the exogenous shock enabled investigations of the differences between online- and campus-based prestigious university education for the same population. The specific design was multiphase, multilevel, and multimethod. The multiphase component involved retrospective ('Fall 2019'), contemporaneous ('Spring 2020'), and prospective (future, nominally 'Fall 2020') elements. The three-level structure involved leaders, faculty, and students. The multiple methods involved thematic analysis of leader interviews and quantitative analysis of data from the faculty and student censuses.

Figure 1 brings together the conceptual and methodological designs and presents the overarching architecture developed to underpin the leader interviews and the student and faculty censuses. It shows the phased nature of the design and data collection and the main constructs. 


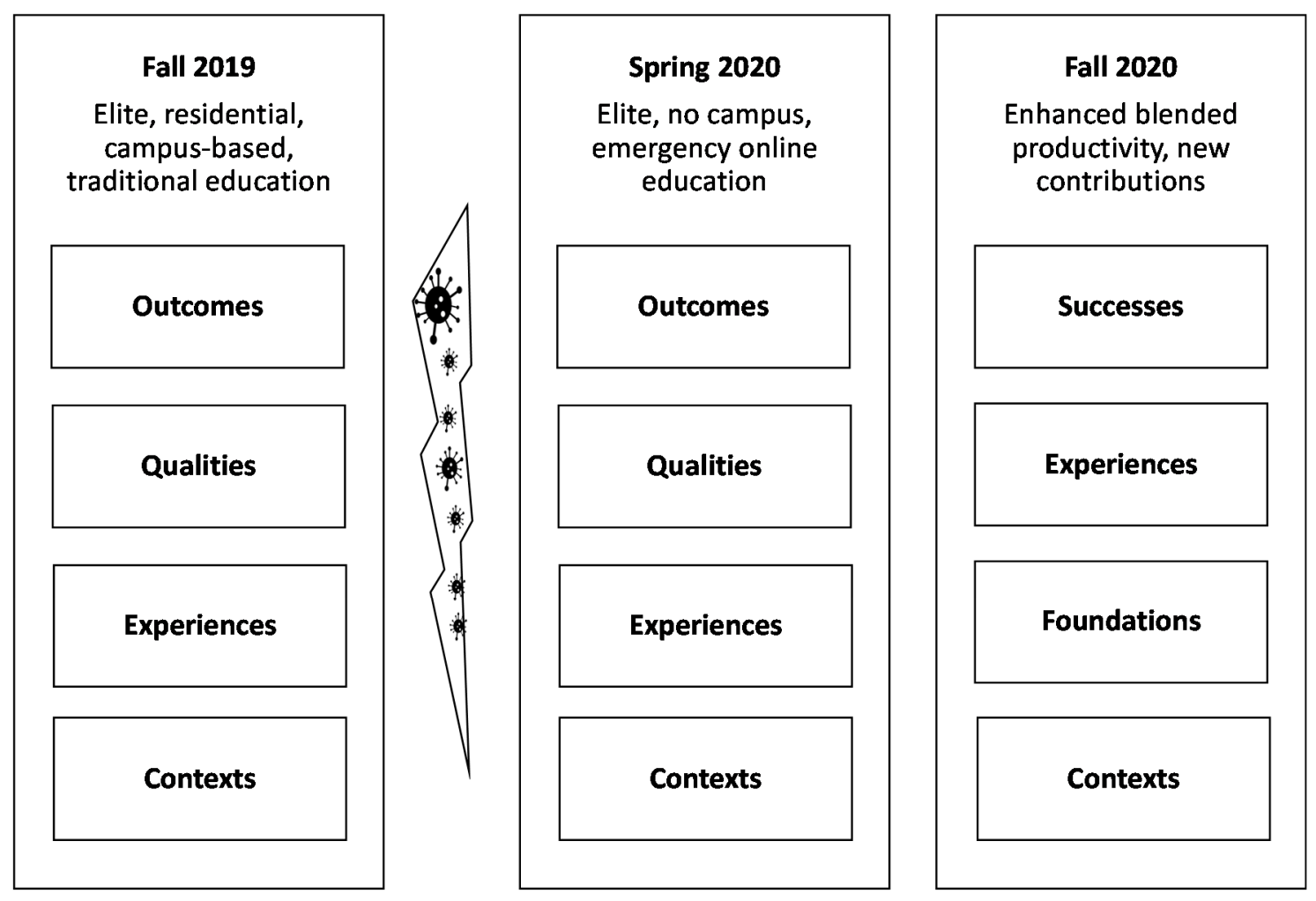

Figure 1. Overarching research conceptual architecture.

\subsection{Instruments}

A series of interlinked questionnaires, as well as an interview schedule, were developed following the design sketched in Figure 1. 'Experiences' refers to broad education experiences, 'qualities' refers to the perceived quality of education, and 'outcomes' refers to perceived education outcomes. The instruments drew extensively on prior research and instruments given the short lead times for development, the opportunity for international benchmarking, and the proven nature of prior materials [11-13]. A series of design principles were defined in terms of response time, language, presentation look and feel, and delivery options. The study was focus on the experience and expectations of students, faculty, and school leaders. The questionnaires were prepared for the body of active students and faculty, while the reflections and insights of school leaders were collected via in depth individual interview.

In the quantitative part of the study, a large number of items were shared between students and faculty, though the exact wording was revised as necessary for each respondent subgroup. For instance, the faculty were asked more items about professional development. Students were asked additional items about learning outcomes. Instrument development involved drafting and collating potential material, dynamic qualitative review, double translation then reconciliation of parallel Chinese and English versions, uploading materials onto online delivering platforms, pilot testing, and extensive proofing, checking, and response testing. As background to the presentation of results, Table 1 lists the constructs, their composite scales, and associated alpha reliabilities. All reliabilities are above 0.70, which is a benchmark value in studies of this kind [14]. 
Table 1. Focus areas and composite scales for broad education experience study.

\begin{tabular}{cccc}
\hline Focus Area & Composite Scale & Reliability & Items \\
\hline \multirow{4}{*}{ Outcomes } & Outcomes Academic Competence & 0.85 & 4 \\
& Outcomes General Skills & 0.92 & 10 \\
& Outcomes Personal Skills & 0.87 & 6 \\
& Outcomes Social Skills & 0.80 & 4 \\
\hline \multirow{5}{*}{ Qualities } & Quality Effective Teaching & 0.88 & 10 \\
& Quality Learning Community & 0.88 & 6 \\
& Quality Learning Resources & 0.91 & 6 \\
& Quality Skills Development & 0.88 & 6 \\
& Quality Student Engagement & 0.89 & 2 \\
& Quality Student Support & 0.73 & 4 \\
\hline \multirow{5}{*}{ Experiences } & Experience Collaboration & 0.71 & 6 \\
& Experience Development & 0.88 & 12 \\
& Experience Enrichment & 0.75 & 8 \\
& Experience Learning & 0.76 & 12 \\
& Experience Research & 0.87 & 6 \\
\hline
\end{tabular}

\subsection{Participants}

Implementation was designed to deliver valid and reliable estimates with efficiency. The level of reporting was the narrow field of education. Formal populations were defined for the three units of analysis, namely leaders, faculty, and students. The leader population included people with institution-wide and faculty-level academic leadership roles. The faculty population was defined as all faculty (including postdoctoral scholars) who were teaching at least one course in Fall 2019 and in Spring 2020. This included a population of 2821 faculty. Half of the total coursework student population were sampled using a proportional stratified random sampling strategy, which generated a sample population of 6561 undergraduates, 2127 masters, and 1308 doctoral students who were participating in coursework in Fall 2019 and Spring 2020. Thirteen leaders were interviewed, and data from these were recorded, transcribed, and translated. The student and faculty censuses and the leader interviews were conducted across the fourth and fifth teaching weeks of the Spring 2020 semester.

\section{Results}

\subsection{Quantitative Results}

Data from the censuses were cleaned and merged, derivative and composite variables were created, and weights were calculated. Item-level missing data was minimal and was treated on a listwise basis. A sampling analysis was conducted, which compared numbers for population, sample, raw responses, and weighted responses. Both weighted and unweighted mean estimates were compared, and the differences were barely notable at two decimal places. Nonetheless, weighting was used to ensure accuracy.

A range of statistical analyses were conducted for the censuses. These included process controls for data integrity and validation checks, psychometric modelling to compile derivative and composite variables and prepare data for analysis, and multilevel longitudinal modelling to give full articulation of complex covariance structures.

In response to the first two research questions, a series of comparisons were conducted between time periods and participation groups to present quantitative results from the student and faculty censuses.

\subsubsection{Difference across Time Periods}

Student and faculty perceptions regarding online learning are different. In order to emphasize the variation of education experience, quality, and outcomes, new variables were generated for students and faculty by subtracting the mean scores for each composite in the fall semester 2019 from those of 
the spring semester 2020. Figures 2 and 3 showed the mean difference of composite scores of student and faculty between the two semesters. It revealed that the faculty reported improved education quality, learning experience, personal development experience, and online learning experience under the new situation.

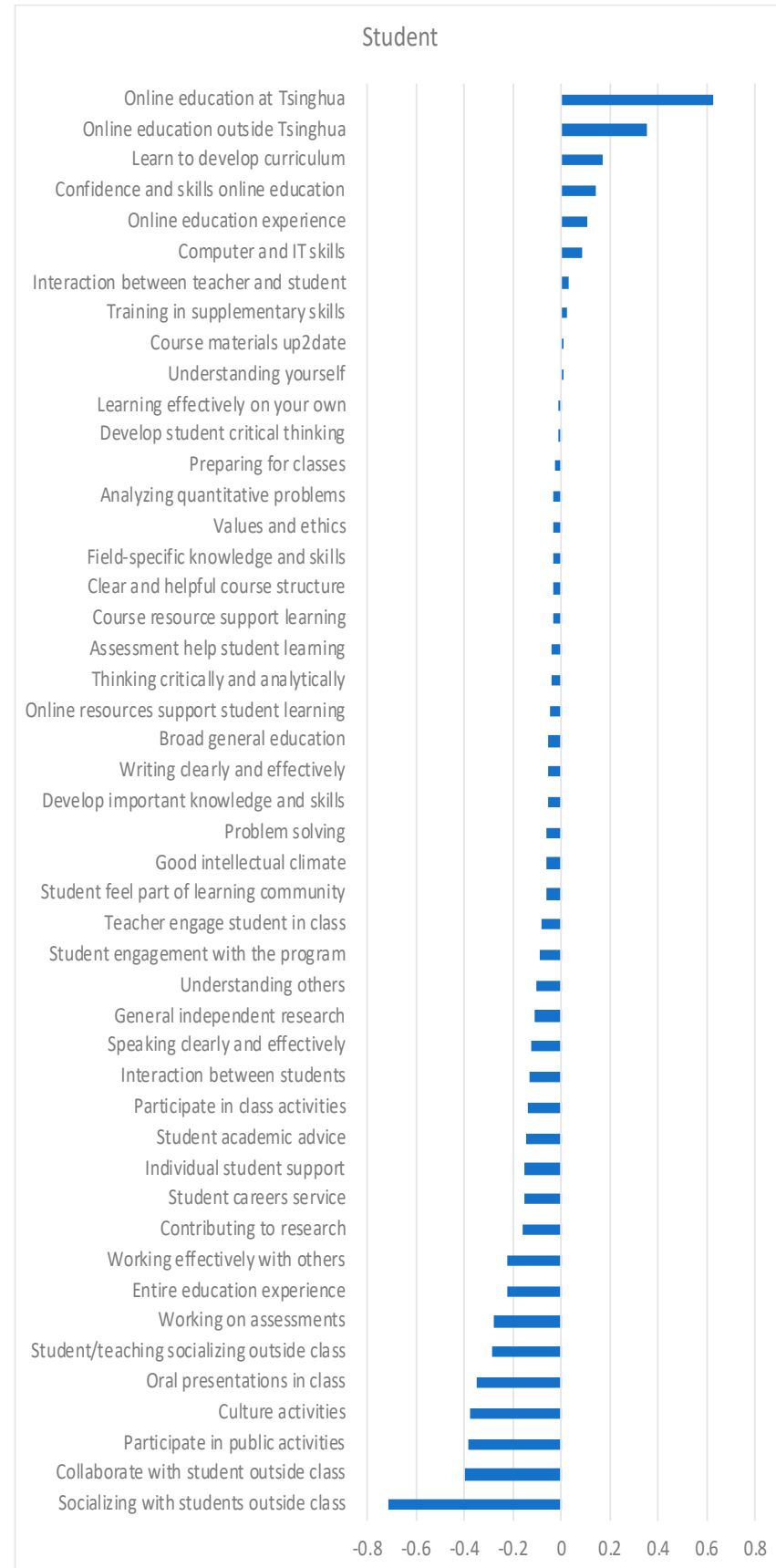

(a)

Figure 2. Cont. 


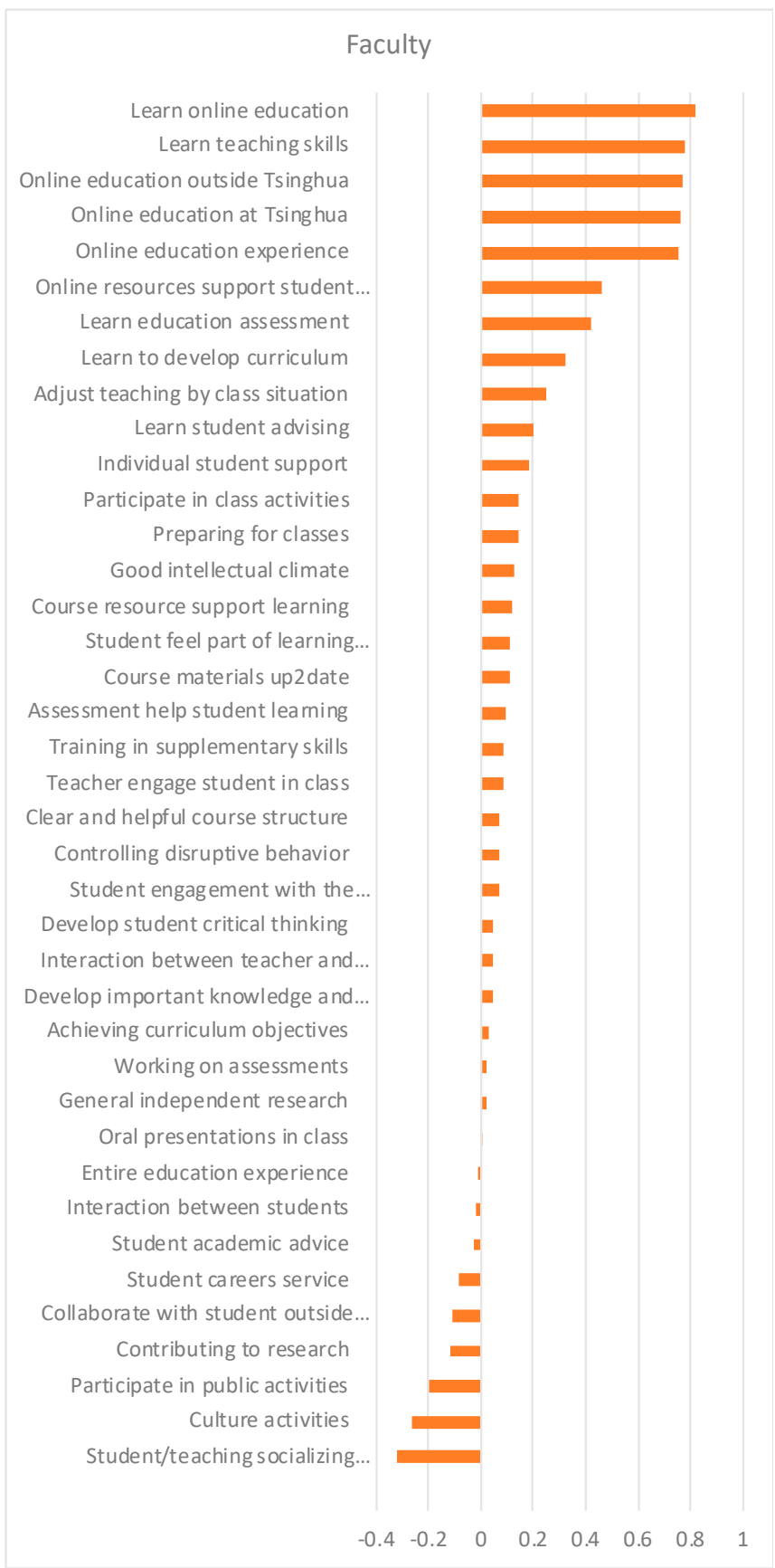

(b)

Figure 2. Item mean differences between Fall 2019 and Spring 2020 semesters. (a) shows the different item mean scores between the two semesters for student samples. (b) shows the different item mean scores between the two semesters for faculty samples. 


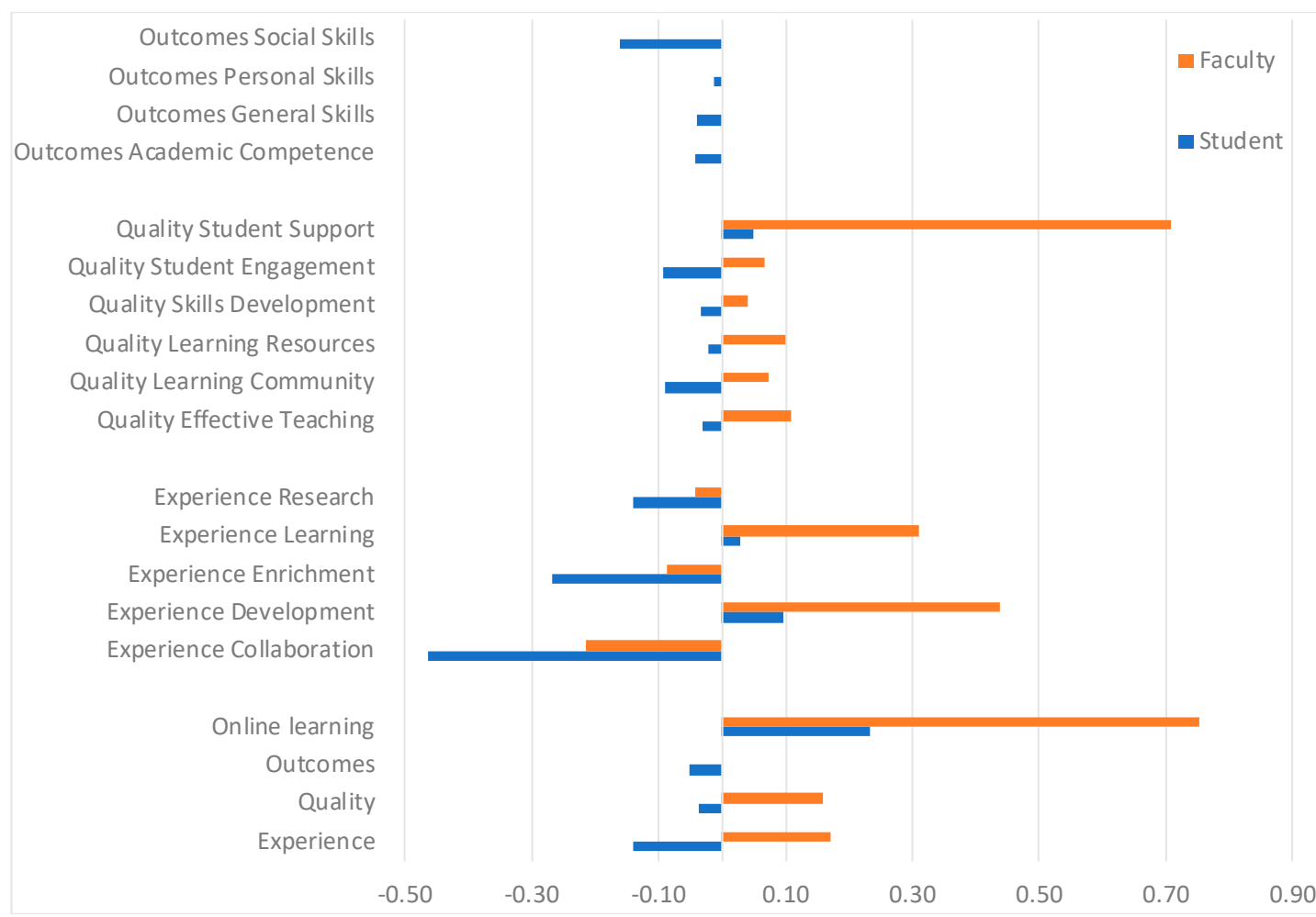

Figure 3. Student and faculty scale mean and standard deviation difference scores between Fall 2019 and Spring 2020 semesters.

However, students' opinions of outcomes, quality, and experience are mainly negative. Notably, faculty and students both agreed that the experience of collaboration has been damaged because of the pure online education mode. This suggests that even though it seems like social media and networks make people more connected than ever before, collaborative activities during learning and teaching are irreplaceable.

Following the research architecture (Figure 1), comparisons were made across groups, time periods, and for a number of demographic and contextual factors. For instance, gender, location, study year level, IT equipment quality, to name a few. Mean/average and standard deviation scores were produced for both focus areas and composition scales (Table 1) and for items in each time period (Fall 2019 and Spring 2020).

\subsubsection{Students Perception of Online vs. Campus-Based Education}

MANOVA was conducted to explore the effect of demographic and contextual factors on the composite scales, aiming to discover significant factors that influence online education experience, quality, and outcomes for students. Students' perception seemed to be non-sensitive to the location where their learning happened. Economic area and rural/urban factors did not show significant effect on education experience, quality, and outcomes. Economic area refers to five major provincial groupings in China [15]. Gender and academic field were not significant factors. There were statistically significant differences in students' perception of education between the two semesters, based on their study year level, GPA quartile, and IT equipment quality. Thus, a series of follow-up univariate ANOVAs were performed to determine how the independent variables affect each of the dependent variables. GPA has a very strong influence on the difference between the two semesters' education quality and outcomes but not on experience. Study year level and IT equipment quality showed a positive significant effect on experience, quality, and outcomes.

Tukey's HSD post hoc analyses were conducted to further explore the mechanism between each level within the independent variables. It was found that although perceptions of experience, 
quality, and outcomes were reasonably consistent across levels of study, there was a significant dip for senior-year undergraduates and master's students. Multiple comparison results showed a significant lower mean score for fourth year undergraduates and first year master's students on the experience, quality, and outcomes difference between the two semesters compared with other grades (Figure 4).
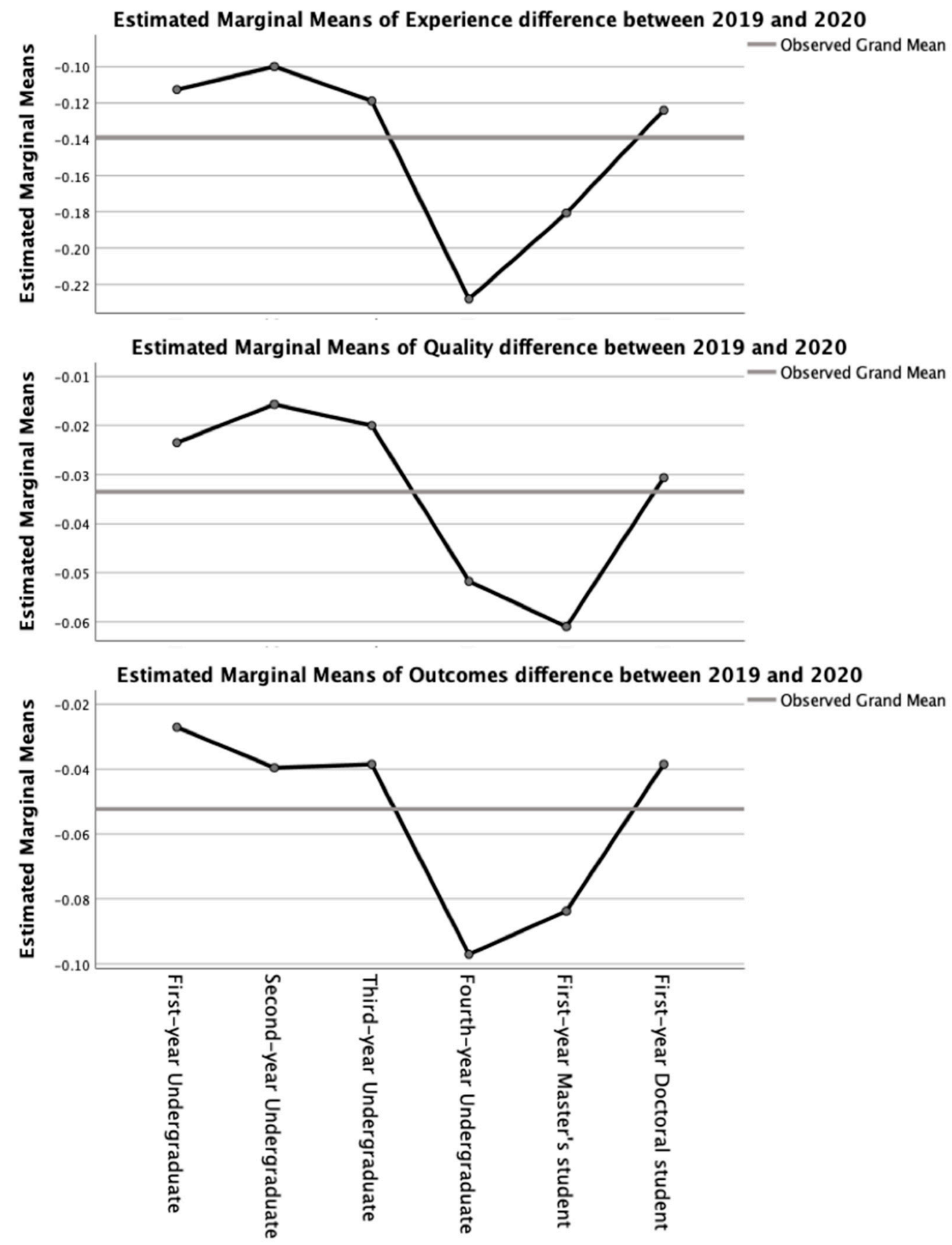

Figure 4. Estimated marginal means of experience, quality, and outcomes difference across student year level between the fall semester 2019 and spring semester 2020. 
GPA quartiles were provided by the academic affairs office and used to categorize students into four levels. Students who reported a GPA in the second highest quartile tended to report worse education experiences. Students in the highest quartile reported lower scores for quality and outcomes (Figure 5).

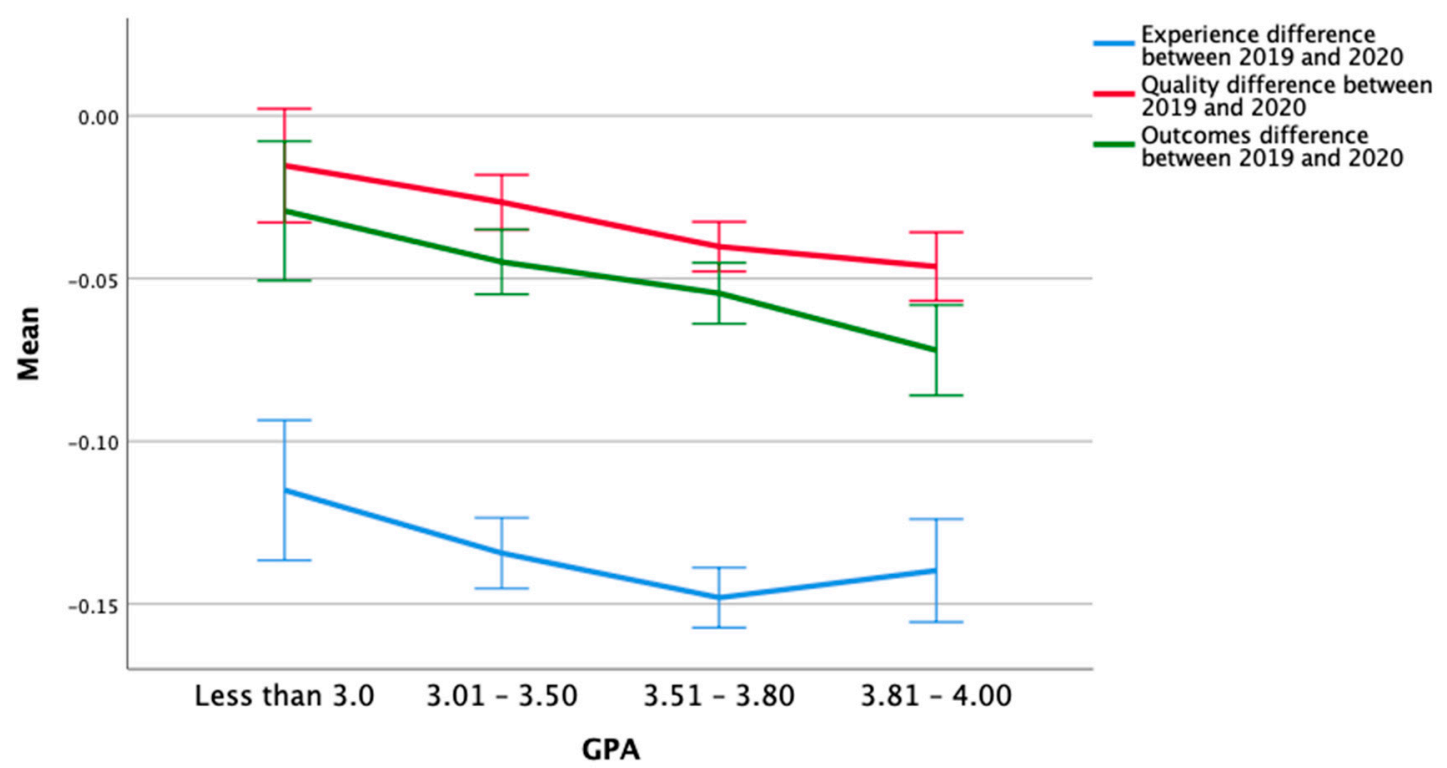

Figure 5. Estimated marginal means of experience, quality, and outcomes difference across GPA quartiles between the fall semester 2019 and spring semester 2020.

IT equipment quality influenced students' experiences, perceptions of quality, and outcomes significantly. It is reasonable that poor and fair IT quality correlates to worse perception of online education versus on-campus education.

\subsubsection{Faculty Perception of Online vs. Campus-Based Education}

Similar to student data, MANOVA was also performed to explore the difference in education experience and quality between the two semesters from the faculty's perspective (Table 2). Economic area and rural/urban factors did not significantly affect faculty education experience and quality. This might because most faculty were in urban areas. Gender and birth year did not show significant effect on faculty experience and quality. IT experience did not make a difference to the faculty as it did for the students. This may be because most teachers were located in urban area therefore secured adequate IT experience during educational activities.

Table 2. Faculty demographic and contextual factors on perceptions of online versus campus experience, quality, and outcomes.

\begin{tabular}{cccc}
\hline & Wilk's $\boldsymbol{\Lambda}$ & $\mathbf{F}$ & $p$-Value \\
\hline Economic area & 0.998 & 1.003 & 0.367 \\
Rural/urban & 0.993 & 2.907 & 0.055 \\
Gender & 0.999 & 0.447 & 0.640 \\
Academic field & 0.991 & 3.924 & $0.020 *$ \\
Work start year & 0.992 & 3.696 & $0.025 *$ \\
Birth year & 0.999 & 0.589 & 0.555 \\
IT equipment quality & 0.998 & 1.067 & 0.344 \\
\hline & $* p 0.05$. &
\end{tabular}


Academic field showed a significant effect on teachers' perceived experience and quality in terms of online versus campus-based teaching. This may suggest that learning strategies may not differ from one discipline to another too much, although it is not the same story for teaching. Disciplines were categorized into five major categories, including Engineering (E); Science; Humanities, Arts, and Social Science (HASS); Medical and Health Sciences; and the interdisciplinary department of Shenzhen International Graduate School. There are four subcategories each under Engineering and HASS, making a total of 11 categories. A follow-up univariate ANOVA and Tukey's HSD post hoc test were performed to further explore the relationship between academic field and semester differences for teaching experience and quality, as shown in Table 3. As mentioned in Section 3.1.1 in Figures 2 and 3 , the overall faculty perceived experience and quality were improved in the spring semester 2020. The post hoc results revealed that engineering fields improved more than HASS fields. Faculty in information technology reported significantly higher quality during online rather than face-to-face teaching, while for management under HASS the estimated marginal mean is relatively low (Figure 6). The nature of these two disciplines may be the reason of the discrepancy. Online teaching is more adaptive to information technology when teachers share course materials and evaluate students' learning achievements. However, for HASS fields, interaction is crucial between teacher and student, as well as between students. As mentioned in Figure 2, collaboration and socialization are constrained when people can only communicate online.

Table 3. Impact of study year level, GPA, and IT equipment quality on perceptions of online versus campus experience, quality, and outcomes among students.

\begin{tabular}{ccccc}
\hline & \multicolumn{2}{c}{ Experience Diff } & \multicolumn{2}{c}{ Quality Diff } \\
\cline { 2 - 5 } & $\mathbf{F}$ & $p$-Value & F & $p$-Value \\
\hline Academic field & 7.304 & $0.007^{* *}$ & 3.970 & $0.047^{*}$ \\
Work start year & 1.181 & 0.278 & 7.309 & $0.007^{* *}$ \\
\hline & $* p<0.05,{ }^{* *} p<0.01$. &
\end{tabular}

Work start year significantly affects faculty's perceived teaching quality between the two semesters but not perceptions of their experience. Two thresholds were set based on national policies. The first was 1998 when China started to expand college enrollment. More teachers were recruited into universities and colleges than ever before. The second threshold was the year 2015. Early in the following year, the Double First-Class initiative was first proposed to improve the overall education quality of top Chinese universities [16]. Both policies deeply influenced faculty employment. Faculty hired between 1998 and 2015 reported a significantly larger difference in quality between Fall 2019 and Spring 2020 than the post-1998 (Mean difference $=0.0556, p=0.001$ ) and post-2016 cohorts (Mean difference $=0.0202$, $p=0.001$.

Overall, the census results convey that students and faculty gave similar reports for online and campus-based education experiences, with the exceptions that interpersonal and enriching experiences were lower, and faculty participation in pedagogical development was higher. Further, students and faculty gave the same quality rating to online and campus education, except that faculty reported a much higher increase in online education experiences, confidence with online education, and providing student support. Importantly, students reported the same outcomes for online and campus education, with the exception of social outcomes, which were lower. 


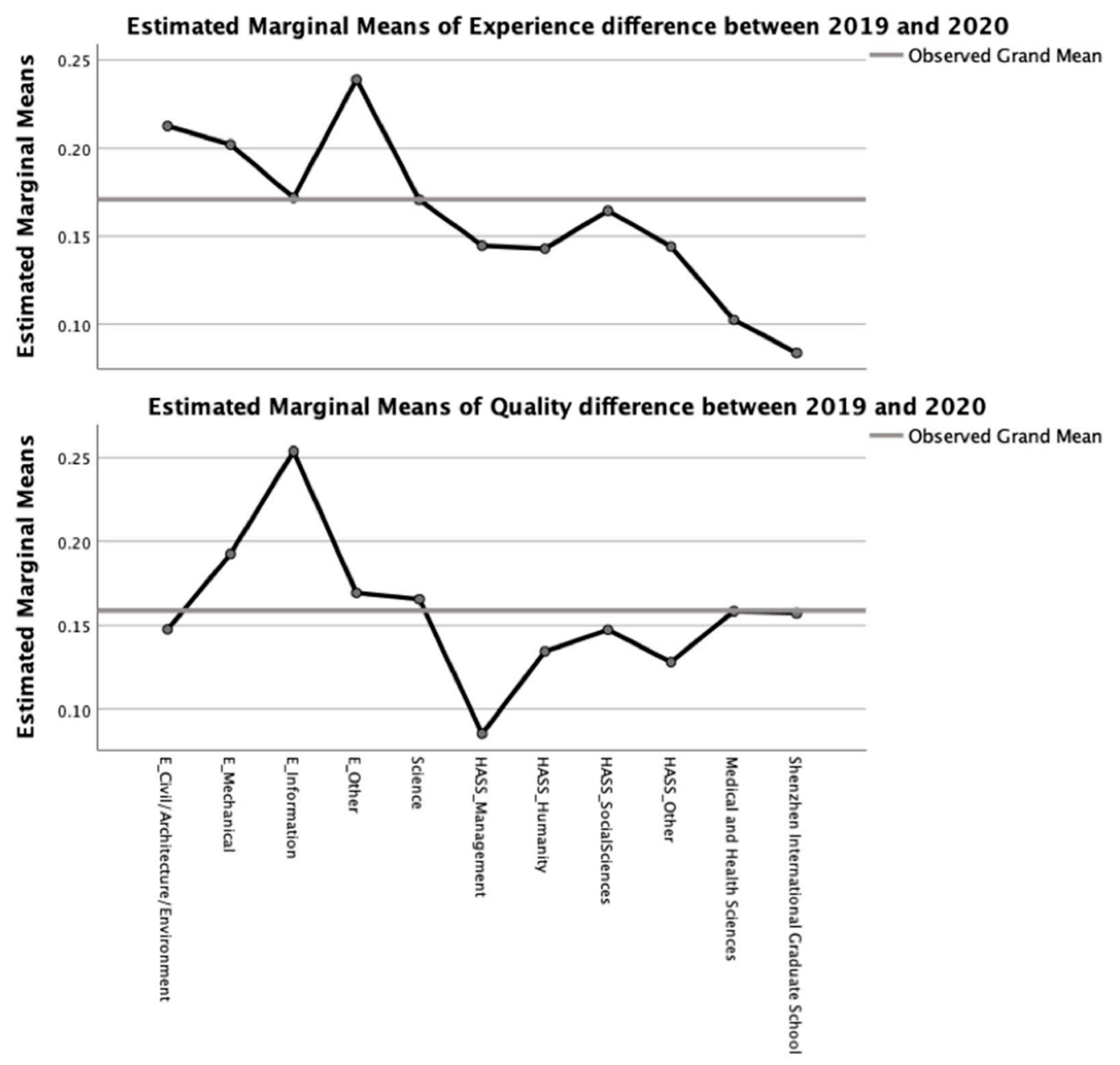

Figure 6. Estimated marginal means of experience and quality difference across faculty in academic fields between the fall semester 2019 and spring semester 2020 .

\subsection{Qualitative Results}

Qualitative data from the student and faculty censuses and from the leader interviews was coded and analyzed thematically. These results regarding experience, quality, and outcomes were reflected in the university leaders' observations. The thirteen leaders commented that:

"The second week of online teaching is much better than the first week. Some teachers also said when chatting that he felt strange at the first class, because it turns out that these teachers are not used to sitting in front of the computer and lecturing in front of the students for many years. So am I. In order to adapt to this teaching mode, I have created a similar simulated teaching environment. I set up a whiteboard. I also attempt to communicate with the students, poke them to answer questions, coordinate discussions and through the rain classroom. Now it seems that I have entered into a good status." (L4)

"At present, more than $80 \%$ of the students report that the effect of online teaching is better than offline teaching. The reason may be that online teaching increases interaction, and each student dares to speak through the bullet screen. The teacher has a selective comment on the speech." (L7)

"Some offline interactive activity such as weekly group meetings can be held online. Students who are going abroad or even graduates can participate into the meeting to share their experience and insights." (L3) 
The census quantitative results were augmented by many thousands of qualitative responses received in Chinese and English from the leaders, students, and faculty, which were coded thematically according to the research architecture in Figure 1. These reveal much about specific areas such as support, curriculum, teaching, assessment, and enrichment.

Support is an important part of people's education experiences. Figure 1 reports that students perceived similar levels of support, though faculty saw emergency online education as involving greater levels of support. The qualitative data helped tease out the different support needs between online compared with intensive campus-based education. For instance, online education requires providing IT help to students to ensure they can study at home; expanding communication and support to students; increasing opportunities for informal interaction with other students; establishing forms of assessment that reward student engagement; training students in how to learn independently online; ensuring that students can access materials, including library materials; providing different and increased opportunities for gathering and acting on feedback; adding additional online careers and psychological counselling supports; and opening greater options for informal communication with faculty and staff.

Obvious curriculum implications arise from a shift to emergency online education. The quantitative results, however, do not reveal meaningful differences regarding curriculum, perhaps due to the existing extensive use of technology in campus teaching. In their qualitative response, students and faculty highlighted the availability of open courseware to facilitate supplementary learning, adapting curriculums to online formats, and making use of internet resources, as well as eliminating redundant materials, eliminating courses and curriculum that are not suitable for online delivery, reducing didactic presentations and opening opportunities for more flexible and self-paced learning, and shifting to experimental classes online using virtual reality. Regarding curriculum and learning resources, the academic leaders observed that:

"We also have hands-on experimental classes. These courses cannot be organized online. Although the virtual experiment can be applied, it is a supplement, not a substitute for hands-on class. So the online teaching is not suitable for all courses." (L6)

"The main disadvantage of online teaching is that it is not face-to-face. "Face-to-face" can not only close the distance, but also provide emotional communication. For example, for anxious students, face-to-face counseling and question-answering are very necessary. Currently, a lot of students are facing learning maladjustment, which is the challenge caused by online teaching." (L7)

"There is a lot of feedback from students: the lack of paper-based courseware and teaching materials; lack of real classroom environment; lack of peer discussion." (L9)

The results reveal much about teaching in general and teaching online. The quantitative results reveal that faculty invested substantially more time in learning about teaching and student support, as well as in preparation and actual teaching. Students and faculty made many observations about teaching in the qualitative response, noting, for instance, that: online coaches could be provided to augment formal lectures, there is a need to ensure that faculty are trained and competent online teachers, there is a need to adapt teaching styles and techniques for online provision, teachers and students should be trained in various facets of online education such as active communication and time management, faculty can make sophisticated use of recording and videoing to enhance and expand education delivery, there is scope to engage and support a wider range of external and visiting scholars in the teaching process, teaching should be highly interactive and focus on communication rather than content delivery, and classes should be 'flipped' such that materials are provided before class, and online classes are focused on interaction. Regarding teaching, the leaders noted that:

"We really worry about the quality of teaching for international students, as they do not interact much online and we do not know how to initiate their motivation." (L2) 
"Students' self-discipline affects the efficiency of online education. Self-discipline is out of our control. If students do not find what teachers are saying interesting, they may just leave the platform open and do their own work." (L9)

While this study was conducted before the main end-of-semester assessments, many courses had already passed through mid-semester assessments. The census results indicated that students saw various forms of assessment and similar contribution as being challenged during emergency online education, although such concern was not evident among the faculty. Students and faculty recommended that there should be more regular homework and feedback to help scaffold and give momentum, that there is a need to develop specialized online assessment tools, that students required greater monitoring and explicit feedback, that collaborative groupwork could enhance student interaction as well as moderate participation and contribution, that distance learning calls would benefit from the adoption of more formative rather than summative forms of assessment, and that emerging techniques and methods could be used to enhance assessment. Observations from the leader interviews about student assessment included that:

"Examinations are such a serious thing that they even have some legal effect. How will we organize the midterm and final? How to guarantee the fairness of that? If the fairness cannot be guaranteed, the teaching order will face challenge." (L7)

"After the second week of this semester, the president immediately focused on scientific research and student graduation. If the work of graduation is not done well, the impact is larger. Although our university had planned to remove the publication requirement for students' graduation, the official documents were never issued. But this is the point at which the university has to deal with this as soon as possible. This involves breakthrough and establishment. Why the university has not issued the documents is that it means "breakthrough", but we also need "establishment". Recently, a whole-process quality document is designed in response to the establishment." (L13)

University is about far more than formal discipline-based learning, which is why the research tapped into a broad notion of education. It focused on formal coursework teaching and learning, and stretched further to embrace, for instance, research experiences, social and interpersonal activities outside classes, clubs, cultural activities and sports, student support in both academic and daily administrative stuff, and career/professional development. Table 1 and Figure 3 convey that it is this broader facet of university study which suffers with emergency online education. The students and faculty identified that more thorough re-engineering would be required by bringing more external and international experts into the teaching process, opening access to a range of courses so that students can augment their formal learning with additional inquiry, enlarging the volume of credits/courses that a student can participate in to diversify a program of study, giving clearer recognition to private study so that time with others can be invested in broader enriching experiences, and providing more fun and social online and careers-related interactions.

\section{Discussion}

This paper has analyzed research revealing that to ensure sustainability, in just a few months leaders, students, staff, and faculty at a major university transformed a prestigious residential research university with limited formal fully online education into what is perhaps the world's most prestigious and programmatically diverse online universities. This transformation, sparked by the viral epidemic, has revealed much about education and the future of universities. By way of conclusion, in response to the third research question, it is helpful to articulate broad insights into the future of university education and associated areas for development.

Most basically, the findings hasten the formation of blended forms of university education. This situation has been bolstered by the global reliance on online emergency learning to deliver core 
education services. Systems, experiences, and expectations have been quickly forged and will almost surely yield widespread and enduring changes for higher education. It is not possible nor seemingly desirable to 'go back' from much that has been experienced. Seemingly, online learning has indeed grown beyond smart acronyms and joined mainstream education [17-19]. Education systems across Asia will almost certainly place more emphasis on formal online education. Such a move holds global consequences, with Asia being the world's biggest time zone for higher education. New regulatory policies and cross-border agreements will be required. Countries will need to negotiate new rules with physical institutions such as campus-based universities, including bolstering the already flourishing emergence of life-long learning.

To ensure sustainability, this broad transformation signals a need for many more specific facets of education reform. It is helpful to spell out specific developments, all of which have already been the product of widescale validation and discussion [2].

The results pertaining to student support convey the need to establish and activate new arrangements that address administrative, academic, and personal problems. The research findings confirm that online teaching platforms, tools and equipment should be basic and low-profile instead of advanced and luxurious, so that everyone can afford and access them without discrimination. Universities will need to ensure that students and faculty have IT equipment that furnishes them with a high-quality experience. As online learning requires more specialized student support, there is a need to create more teaching assistant positions and enhance training to ensure high-quality support for faculty and students. More ambitiously, different kinds of 'academic success professionals' who focus persistently on student success by integrating student support, academic administration, and individualized learning are likely required. Learning alone in a room with a computer, even with videoconferencing, is a very different social and personal experience to learning in-person with peers. Students must be even more active and collaborative, self-directed and supported [20]. To enhance education equity and achievement, students will need academic skills training on how to succeed in blended education environments so that they can regulate and enrich their learning.

The findings convey that with shifts to online education, universities should ensure that relevant curriculum materials are adapted for online delivery by drawing on progress made by large education service firms and engaging 'professional education engineers' in curriculum reviews and quality verifications. More fundamentally, as part of this research it was proposed that the shock could well lead universities across China, Asia, and the world to consider the nature of the course and look at sharing courses and recognizing credits to maximize student and institutional benefit. This kind of transformation is already reflected in shifts towards micro-credentials, lifelong learning, and open courseware, and it would be accelerated if propelled by leading research universities [21,22]. Universities and faculty can design core education services that shift information dissemination online and magnify the social, interpersonal, and enriching facets of campus education.

Teaching stands out as an area for reform. Online teaching has to be much more programmed than campus-based provision, requiring specific training of faculty. Faculty will need support to grow into this new environment through training in pedagogy, building relationships with teaching support staff, learning how to exploit software to enhance academic productivity and success, and adapting to greater transparency. The findings convey that to enhance teaching, universities should design and provide an exciting array of professional development for faculty, and teaching faculty are encouraged to complete training in online education that enhances basic teaching techniques, looks at the elements of student success, and discusses problems and workarounds.

Assessment remains an area in need of substantial educational reform. Results from this research affirmed that universities must urgently investigate the development of sophisticated and productive online assessment education technology [23,24]. Universities will need to make substantial investments in bringing to scale robust solutions for assessing student learning, finally integrating academic leadership, assessment methodology, and education technology. 
Shifting formal learning online carries basic consequences for the broader enriching facets of university education. Online learning was more supportive of individual needs than social study. Clearly, campus-, field- and travel-based forms of education and exchange are hindered with emergency online education. Nonetheless, the study affirmed that online provision can be used to make formal learning more flexible, diversify formal learning, and open access to additional enrichment experiences.

Underpinning such education reform is needed to improve management and assurance of quality. It is disturbing that even after two decades of growth, very little is known about the quality of online education, and little if any management information is available [19]. Governments and quality assurance agencies remain rightly uncertain, and hence skeptical, about the characteristics, quality, and contribution of learning online [25]. Novel forms of quality governance are required to ensure success when IT is added to education practice [26]. Universities will need to routinely collect large volumes of data on education, requiring the formation of new theories, new analytical and reporting techniques, and new strategies for helping people interpret patterns and identify consequences. University quality assurance and enhancement must change to take account of changes in education such as greater scale, online communication, contemporary platforms and data, and new forms of collaboration.

Research on this scale generates results and findings with many implications. In addition to responding to the research questions, the infrastructure, methods, results, and outcomes developed through this research make broader contributions. The research gives guidance on how to blend online and campus education in productive ways. It clarifies quality and productivity indicators for technologically distributed education at prestigious research universities. It has produced data collection instruments for ongoing quality monitoring. Importantly, it has established baseline data for ongoing evaluation and continuous improvement. Combined, these implications cement a need for increased research into online education, engaging research not only into online technologies but also exploring basic questions about quality and standards, basic characteristics, and social and emotional implications.

Overall, this research shows that education technology can be readily deployed in highly sustainable and productive ways that extend traditional university boundaries and engage a much larger and more diverse range of people in purposeful academic activities. The formation of blended education communities carries the potential to reshape international patterns of study, assure the sustainability of learning, expand global partnerships, make major contributions to life-long learning, re-parcel learning into smaller resources, reshape the way achievement is recognized, and spawn new kinds of credentials. Clearly, these insights are just summary observations from a very large, rapid, and ambitious research project. It is essential that ongoing research is conducted to monitor progress and generate insights that can help create and guide future university transformation.

Author Contributions: Y.L. contributed to all facets of the research design, delivery and documentation. Y.Z. contributed to all facets of the research design, delivery and documentation. W.Q. contributed to translation, data analysis and reporting. L.Z. contributed to translation, data analysis and reporting. H.C. contributed to all facets of the research design, delivery and documentation. All authors have read and agreed to the published version of the manuscript.

Funding: This research was funded by the "Dual High" Tsinghua Humanity Development Project.

Acknowledgments: The researchers thank the many people and offices who helped ensure the value and contribution of this research. This research is funded by the ‘Dual High' Tsinghua Humanity Development Project.

Conflicts of Interest: The authors declare no conflict of interest on this piece of work.

\section{References}

1. Jack, A.; Smyth, J. Coronavirus: Universities Face a Harsh Lesson. 2020. Available online: https://www.ft. com/content/0ae1c300-7fee-11ea-82f6-150830b3b99a (accessed on 22 August 2020). 
2. Qiu, Y. Special Dialogue on Online Education in the COVID-19 Response and Beyond. 2020. Available online: https://en.unesco.org/events/special-dialogue-online-education-covid-19-response-and-beyond (accessed on 22 August 2020).

3. Coates, H.; Liu, L.; Zhong, Z.; Liu, L.; Hong, X.; Gao, X. International Innovation in Online Higher Education Services: Framing Opportunities in China; Online Education Services: Melbourne, Australia, 2019.

4. Wong, E. New Insights into Contemporary Higher Education in the US: Framework of Online Program Management (OPM) Providers and Its Implication for China; Schwarzman College: Beijing, China, 2019.

5. HolonIQ. Data-Driven Research. 2020. Available online: https://www.holoniq.com/research/ (accessed on 22 August 2020).

6. Shanghai Ranking. Academic Ranking of World Universities 2019: China. 2019. Available online: www.shanghairanking.com/World-University-Rankings-2019/China.html (accessed on 22 August 2020).

7. Shanghai Ranking. Shanghai Ranking's Global Ranking of Academic Subjects 2019: Computer Science and Engineering. 2019. Available online: www.shanghairanking.com/Shanghairanking-Subject-Rankings/ computer-science-engineering.html (accessed on 22 August 2020).

8. Jing, M. Zhongguancun: Beijing's Innovation Hub Is at the Center of China's Aim to Become a Tech Powerhouse. 2018. Available online: https://www.scmp.com/tech/start-ups/article/2172713/zhongguancunbeijings-innovation-hub-centre-chinas-aim-become-tech (accessed on 22 August 2020).

9. Cantwell, B.; Coates, H.; King, R. (Eds.) Handbook on the Politics of Higher Education; Edward Elgar: Cheltenham, UK, 2018.

10. Hazelkorn, E.; Coates, H.; McCormick, A. (Eds.) Research Handbook on Quality, Performance and Accountability in Higher Education; Edward Elgar: Cheltenham, UK, 2018.

11. Radloff, A.; Coates, H. Doing More for Learning: Enhancing engagement and Outcomes. Australasian Student Engagement Report; Australian Council of Educational Research: Camberwell, UK, 2010.

12. Radloff, A.; Coates, H.; James, R.; Krause, K. Development of the University Experience Survey (UES); Department of Education, Employment and Workplace Relations: Canberra, Australia, 2012.

13. Coates, H.; Croucher, G.; Moore, K.; Weerakkody, U.; Dollinger, M.; Grosemans, I.; Bexley, E.; Kelly, P. Contemporary Perspectives on the Australian Doctorate: Framing Insights to Guide Development. Available online: https://www.tandfonline.com/doi/full/10.1080/07294360.2019.1706451 (accessed on 22 August 2020).

14. Griffin, P.; Coates, H.; McInnis, C.; James, R. The development of an extended Course Experience Questionnaire. Qual. High. Educ. 2003, 9, 259-266. [CrossRef]

15. National Bureau of Statistics of China. The East, Middle, West, and Northeast Economic Area. Available online: http://www.stats.gov.cn/ztjc/zthd/sjtjr/dejtjkfr/tjkp/201106/t20110613_71947.htm (accessed on 22 August 2020).

16. Ministry of Education of China. Work plan of the Ministry of Education in 2016. Available online: http://www.moe.gov.cn/srcsite/A02/s7049/201602/t20160205_229509.html (accessed on 22 August 2020).

17. Kentnor, H.E. Distance education and the evolution of online learning in the United States. Curric. Teach. Dialogue 2015, 17, 21-34.

18. Yuan, L.; Powell, S.J.; Olivier, B. Beyond MOOCs: Sustainable Online Learning in Institutions; Centre for Educational Technology, Interoperability and Standards (Cetis), 2014. Available online: https://publications. cetis.org.uk/2014/898 (accessed on 22 August 2020).

19. Palvia, S.; Aeron, P.; Gupta, P.; Mahapatra, D.; Parida, R.; Rosner, R.; Sindhi, S. Online education: Worldwide status, challenges, trends, and implications. J. Glob. Inf. Technol. Manag. 2018, 21, 233-241. [CrossRef]

20. Thorpe, M. Rethinking learner support: The challenge of collaborative online learning. Open Learn. J. Open Distance E Learn. 2002, 17, 105-119. [CrossRef]

21. Castaño Muñoz, J.; Redecker, C.; Vuorikari, R.; Punie, Y. Open Education 2030: Planning the future of adult learning in Europe. Open Learn.: J. Open Distance E Learn. 2013, 28, 171-186.

22. Lemoine, P.A.; Richardson, M.D. Micro-credentials, nano degrees, and digital badges: New credentials for global higher education. Int. J. Technol. Educ. Mark. (IJTEM) 2015, 5, 36-49. [CrossRef]

23. Coates, H. Next Generation Assessment. Available online: https://www.ncsl.org/research/education/nextgeneration-assessments.aspx (accessed on 22 August 2020).

24. Coates, H.; Zlatkin-Troitschanskaia, O. The governance, policy and strategy of learning outcomes assessment. High Educ. Policy 2019, 32, 507-512. [CrossRef] 
25. Zhao, F. Enhancing the quality of online higher education through measurement. Qual. Assur. Educ. 2003, 11, 214-221. [CrossRef]

26. Dykman, C.A.; Davis, C.K. Online education forum-part three: A quality online educational experience. J. Inf. Syst. Educ. 2008, 19, 281.

(C) 2020 by the authors. Licensee MDPI, Basel, Switzerland. This article is an open access article distributed under the terms and conditions of the Creative Commons Attribution (CC BY) license (http://creativecommons.org/licenses/by/4.0/). 